\title{
A high-density genetic map and QTL mapping of leaf traits and glucosinolates in Barbarea vulgaris
}

Tong-jin Liu', You-jun Zhang ${ }^{1}$, Niels Agerbirk², Hai-ping Wang ${ }^{1}$, Xiao-chun Wei ${ }^{3}$, Jiang-ping Song ${ }^{1}$, Hong-ju He ${ }^{4}$, Xue-zhi Zhao ${ }^{4}$, Xiao-hui Zhang ${ }^{1 *}$ and Xi-xiang Li $i^{*}$

\begin{abstract}
Background: Barbarea vulgaris is a wild cruciferous plant and include two distinct types: the G- and P-types named after their glabrous and pubescent leaves, respectively. The types differ significantly in resistance to a range of insects and diseases as well as glucosinolates and other chemical defenses. A high-density linkage map was needed for further progress to be made in the molecular research of this plant.

Results: We performed restriction site-associated DNA sequencing (RAD-Seq) on an $F_{2}$ population generated from G- and P-type B. vulgaris. A total of 1545 SNP markers were mapped and ordered in eight linkage groups, which represents the highest density linkage map to date for the crucifer tribe Cardamineae. A total of 722 previously published genome contigs (50.2 Mb, 30\% of the total length) can be anchored to this high density genetic map, an improvement compared to a previously published map (431 anchored contigs, $38.7 \mathrm{Mb}, 23 \%$ of the assembly genome). Most of these (572 contigs, $31.2 \mathrm{Mb}$ ) were newly anchored to the map, representing a significant improvement. On the basis of the present high-density genetic map, 37 QTL were detected for eleven traits, each QTL explaining 2.9-71.3\% of the phenotype variation. QTL of glucosinolates, leaf size and color traits were in most cases overlapping, possibly implying a functional connection.

Conclusions: This high-density linkage map and the QTL obtained in this study will be useful for further understanding of the genetic of the B. vulgaris and molecular basis of these traits, many of which are shared in the related crop watercress.
\end{abstract}

Keywords: Barbarea vulgaris, Restriction site-associated DNA sequencing (RAD-Seq), Genetic linkage map, QTL, Leaf traits, Glucosinolates

\section{Background}

Barbarea vulgaris $(2 \mathrm{n}=2 \mathrm{x}=16)$ is a wild crucifer with an estimated genome size of $270 \mathrm{Mb}$ [1]. It originated in the Mediterranean area and now occurs in temperate regions worldwide [2]. There are two morphologically, chemically and biologically distinct types of $B$. vulgaris: the G-type named after its glabrous leaves and the P-type named after its pubescent leaves [3-5]. The G-type is strongly resistant to two important agricultural pests, the diamondback moth (Plutella xylostella) and

\footnotetext{
* Correspondence: zhangxiaohui01@caas.cn; lixixiang@caas.cn ${ }^{1}$ Institute of Vegetables and Flowers, Chinese Academy of Agricultural Sciences; Key Laboratory of Biology and Genetic Improvement of Horticultural Crops, Ministry of Agriculture, Beijing 100081, China Full list of author information is available at the end of the article
}

western flower thrips (Frankliniella occidentalis), while the P-type is completely susceptible to them [6-8]. A similar pattern was reported for a range of other herbivorous insects and mollusks [3, 9] and the powdery mildew fungus Erysiphe cruciferarum [8]. In contrast, the G-type was reported to be susceptible to the oomycete Albugo candida while the P-type was resistant to it [10]. The G- and P-types differ in the composition of glucosinolates, flavonoids and saponins, which are secondary metabolites known to play important roles in plant resistance to a series of biotic and abiotic stresses [11-15]. The G-type B. vulgaris is resistant to the diamondback moth and the flea beetle Phyllotreta nemorum due to its content of triterpenoid saponins, a unique

(C) The Author(s). 2019 Open Access This article is distributed under the terms of the Creative Commons Attribution 4.0 International License (http://creativecommons.org/licenses/by/4.0/), which permits unrestricted use, distribution, and 
feature among crucifers $[6,16-18]$, while the difference in Albugo candida resistance between G- and P-type plants could possibly be related to differences in glucosinolate composition and hydrolysis products [12] or glucosinolate derived phytoalexins $[19,20]$.

The above findings define Barbarea vulgaris as an important genetic resource for pest and disease resistance as well as genes responsible for glucosinolates and saponins. Glucosinolates are highly attractive for diamondback moth oviposition, while deterrence conferred by saponins kill the resulting larvae. Thus G-type B. vulgaris has a potential use in 'dead-end trap cropping' for diamondback moth management [21-23]. Another important goal of $B$. vulgaris research is to confer resistance traits (resistance to diseases and pests, cold tolerance, etc.) to cultivated crucifers. To achieve this goal, intertribal somatic hybridization between Brassica napus and B. vulgaris was tried but the hybrid plants could grow under in vitro conditions but not be recovered, revealing compatibility problems between the species [24]. Due to more recent progress in genetic transformation technology [25-27], identification of resistance genes in B. vulgaris can benefit from biotechnology-based breeding of cruciferous crops.

QTL (Quantitative Trait Locus) mapping is an effective approach widely used to identify genes determining a certain trait [28]. The creation of a genetic map using molecular markers is the first step in QTL mapping. Three previous reports have investigated the construction of the linkage maps of $B$. vulgaris and genetic dissection of its resistance to flea beetle larvae, using the same $\mathrm{P} \times \mathrm{G}$-type derived $\mathrm{F}_{2}$ population. The first genetic linkage map included 100 AFLP (Amplified Fragment Length Polymorphism) and 31 SSR (Simple Sequence Repeat) markers with a total length of $889 \mathrm{cM}$ and an average marker distance of $7.1 \mathrm{cM}$ [14], which were distributed acroos eight linkage groups in agreement with the chromosome number [14, 29]. In the second genetic linkage map, more SSR markers were added to first linkage map resulting in a new linkage map. They were distributed on 17 linkage groups, which did not correspond to the chromosome number [30]. More recently, a high-density genetic map comprising 796 SNP markers on eight linkage groups was constructed using the same $\mathrm{P} \times \mathrm{G}$-type derived $\mathrm{F}_{2}$ population by a genotype-by-sequencing approach [1]. This map was used to anchor 431 contigs $(38.7 \mathrm{Mb}, 23 \%$ of the assembly genome) in the $B$. vulgaris whole-genome sequencing project [1]. However, this map is still not sufficiently dense because of the limitation of the relatively small mapping population [31, 32], leading to reported difficulties in molecular studies of $B$. vulgaris defenses $[1,17,30]$. A higher density map would hence benefit $B$. vulgaris genome anchoring and fine mapping of QTL.
In this study, by application of Restriction site-associated DNA sequencing (RAD-Seq) strategies and expansion of the mapping population to 255 individuals, a new highdensity linkage map with 1545 SNP markers was constructed. The genetic map allowed us to anchor 722 contigs from the sequenced G-type B. vulgaris. We further used this map to identify QTL underlying trichome density, maximum leaf length and width, color and glucosinolates of rosette leaves.

\section{Results}

\section{RAD sequencing, SNPs detection and genotyping}

In the present study, a total of $137.4 \mathrm{G}$ (average $539.0 \mathrm{Mb}$ per plant) raw data was generated by Illumina HiSeq platform sequencing from the $F_{2}$ population and $134.5 \mathrm{G}$ (527.6 Mb per plant on average) high-quality clean data was obtained after trimming adaptors and filtering out low quality reads. For the two parents, significantly higher depth sequencing was performed, generating $3.3 \mathrm{G}$ and 3.5 G clean data for G-type and P-type plants, respectively. After removal of redundancy, 7,479,898 and 8,271,583 RAD-tags were identified from the G-type and P-type plants, respectively (Additional file 1: Figure S1a). The $F_{2}$ individuals had an average of 1,277,043 tags (Additional file 1: Figure S1a). The sequencing depth of the RAD-tags was $43.93 \times$ for the G-type, $44.20 \times$ for the P-type, ranging from 7.07 to 12.53 with an average of $8.82 \times$ for $F_{2}$ individuals (Additional file 1: Figure S1b).

The RAD-tags from G-type and P-type plants were assembled to 114,989 and 125,940 contigs with the total length of 37,549,170 and 39,800,608 bp, respectively (Table 1). The average contig length of G- and P-type was 326 and $316 \mathrm{bp}$ with N50 sizes of 389 and $383 \mathrm{bp}$, respectively (Table 1). The assembled P-type contigs were used as reference for SNP discovery.

Between G-type and P-type B. vulgaris, a total of 80,928 SNPs were identified ( $1 \mathrm{SNP} / 2 \mathrm{~kb})$ (Table 2 ). Among these, 60,287 co-dominant "aa $\times$ bb" type SNPs were identified (Table 2). Subsequently, the polymorphic markers were detected in the $F_{2}$ population, resulting in 8448 SNPs that were present in at least 216 plants $(85 \%$ of the population). After segregation distortion filtering with $P$-value $<0.001$, the remaining 2052 SNP markers were finally used for linkage map construction.

Table 1 Summary statistics of G- and P-type Barbarea vulgaris contigs assembly

\begin{tabular}{llllll}
\hline Sample & $\begin{array}{l}\text { Total contig } \\
\text { base (bp) }\end{array}$ & $\begin{array}{l}\text { Total contig } \\
\text { number }\end{array}$ & $\begin{array}{l}\text { Average contig } \\
\text { length (bp) }\end{array}$ & $\begin{array}{l}\text { N50 } \\
\text { length } \\
\text { (bp) }\end{array}$ & GC (\%) \\
\hline G & $37,549,170$ & 114,989 & 326 & 389 & 36.42 \\
P & $39,800,608$ & 125,940 & 316 & 383 & 36.86 \\
\hline
\end{tabular}


Table 2 Numbers of markers for four segregation types

\begin{tabular}{ll}
\hline Marker Type & Number \\
\hline $\mathrm{nn} \times \mathrm{np}$ & 7920 \\
$\mathrm{aa} \times \mathrm{bb}$ & 60,287 \\
$\mathrm{Im} \times \|$ & 11,786 \\
$\mathrm{hk} \times \mathrm{hk}$ & 935 \\
Total markers & 80,928
\end{tabular}

"II", "aa", homozygous genotype as in paternal; "Im", heterozygous genotype as in maternal; " $n n^{\prime \prime}$ " "bb", homozygous genotype as in maternal; "np", heterozygous genotype as in paternal; " $h h^{\prime}$, "kk", homozygous genotype in $\mathrm{F}_{1}$ progeny, and

"hk" types represent heterozygous genotype as in paternal or maternal

\section{Linkage map construction}

Before construction of linkage maps, 286 similar SNP sites (similarity $>0.95$ ) were excluded and the remaining markers were divided into eight groups using JoinMap 4.0. As a result, severely unlinked markers were excluded, and 1545 markers were mapped onto eight linkage groups (LGs) with a total length of $567.996 \mathrm{cM}$ and an average distance of $0.381 \mathrm{cM}$ between adjacent markers (Fig. 1, Table 3). On this map, LG3 (110.97 cM including 219 markers) and LG2 (33.804 cM including 168 markers) achieved the longest and shortest genetic distance. LG8 and LG4 had the highest and lowest marker number, 257 markers spanning $61.482 \mathrm{cM}$ and 146 markers spanning $62.723 \mathrm{cM}$, respectively. The average gaps between adjacent markers of individual LGs varied from 0.202 to $0.582 \mathrm{cM}$ (Table 3).

\section{Anchoring the contigs}

The present linkage map was used to anchor contigs generated by a previous genome sequencing project [1]. The markers harboring RAD-Seq contigs of the genetic linkage map were aligned to the $B$. vulgaris genome contigs. As a result, excluding 16 SNP markers, 1, 529 SNP markers were mapped to a total of 722 contigs with a physical length of $50.2 \mathrm{Mb}$. Some contigs were anchored by more than one SNP marker (Fig. 2, Additional file 2: Table S1 and S2). Our map contains 150 contigs (with a total physical length of $19.0 \mathrm{Mb}$ ) which were also anchored on the published B. vulgaris genome [1]. Using these 150 shared contigs, the linkage groups were numbered in accordance with the previous one (Fig. 2). In addition, 572 contigs covering $31.2 \mathrm{Mb}$ of physical length were newly anchored on the current map (Additional file 2: Table S2).

\section{QTL for trichomes, leaf size, color and glucosinolates}

QTL analysis was performed for trichome density, leaf size, color and glucosinolates in the $\mathrm{F}_{2}$ population (Fig. 3 and Table 4). Two QTL associated with trichome density were identified on linkage groups (LG) 4 and 8, explaining 4.8 and $14.0 \%$ of the phenotypic variance, respectively. The additive effects of these QTL are negative values, in accordance with the fact that trichome density was contributed by P-type B. vulgaris (Table 4 ).

QTL associated with maximum leaf length were identified on LG3 and LG6, explaining 5.9 and $19.7 \%$ of the phenotypic variance, respectively. QTL associated with maximum leaf width were identified on LG3, 4, 5, 6 and 7, explaining $6.2,8.7,12.9,7.8$ and $9.4 \%$ of the phenotypic variance. The QTL for leaf length and width on both LG3 and LG6 overlapped, while the additional QTL for leaf width did not reveal any relationship to leaf length.

The leaf color data were divided into three parameters, L (lightness), $\mathrm{a}^{*}$ (redness and greenness) and $\mathrm{b}$ * (yellowness and blueness), for QTL analysis. Six, five and five QTL were identified to associate with $\mathrm{L}$, $\mathrm{a}^{*}$, and $\mathrm{b}^{*}$, explaining $39.7,42.8$ and $37.0 \%$ of the total phenotypic variance of these traits, respectively. These QTL exhibited a complex organization, including both overlap and independent occurrence. Four out of five QTL for both $\mathrm{a}^{*}$ or $\mathrm{b}^{*}$ and three out of six QTL for L were overlapping with at least one other leaf color QTL. The QTL located at $79.1-95.6 \mathrm{cM}$ on LG3 and at $6.8-10.0 \mathrm{cM}$ on LG4 contributed to both $\mathrm{a}^{*}$ and $\mathrm{b}^{*}$; a QTL located at 37.2$58.0 \mathrm{cM}$ on LG7 contributed to both $\mathrm{a}^{*}$ and L; a QTL located at $7.8-20.9 \mathrm{cM}$ on LG5 contributed to both $\mathrm{b}^{*}$ and L; and a QTL located at 72.9-92.7 cM on LG7 contributed to all of $\mathrm{a}^{*}, \mathrm{~b} *$ and L. In contrast, a QTL at LG3, a QTL at LG7, and two QTL at LG4 and one QTL at LG6 controlled the parameters $\mathrm{a}^{*}, \mathrm{~b}^{*}$ and $\mathrm{L}$ independently.

The contents of seven glucosinolates were scored in leaves of the G-, P- type and $F_{2}$ individuals. In the HPLC-analyses, para-hydroxyglucobarbarin and parahydroxyepiglucobarbarin desulfo derivatives coeluted, so only the sum of them was scored (Additional file 2: Table S3) and used in attempts to locate QTL responsible for para-hydroxylation. Twelve QTL for five glucosinolates were detected on linkage group 3, 4, 5 and 6, each QTL explaining 2.9-71.3\% of the phenotypic variation (PVE) (Fig. 3 and Table 4). One group of overlapping QTL at the upper end of LG4 contributed to 42.3 and $19.3 \%$ of the PVE for 2-phenylethylglucosinolate (gluconasturtiin, NAS), $41.6 \%$ of the PVE for $(2 S)$ 2-hydroxy-2-phenylethylglucosinolate (glucobarbarin, BAR) and $71.3 \%$ of the PVE for (2R)-2-hydroxy-2-phenylethylglucosinolate (epiglucobarbarin, EBAR). Hence, this QTL was the main locus determining levels of all three phenylalanine derived glucosinolates in $B$. vulgaris. However, at the lower end of LG3, overlapping QTL explaining 12.5\% PVE of BAR and 6.4\% PVE of EBAR were found. Both of these loci displayed strong positive additive effect for BAR and strong negative additive effect for EBAR, indicating a pair of alleles competitively regulating the biosynthesis of this pair of isomers. Two additional QTL for the glucobarbarins 


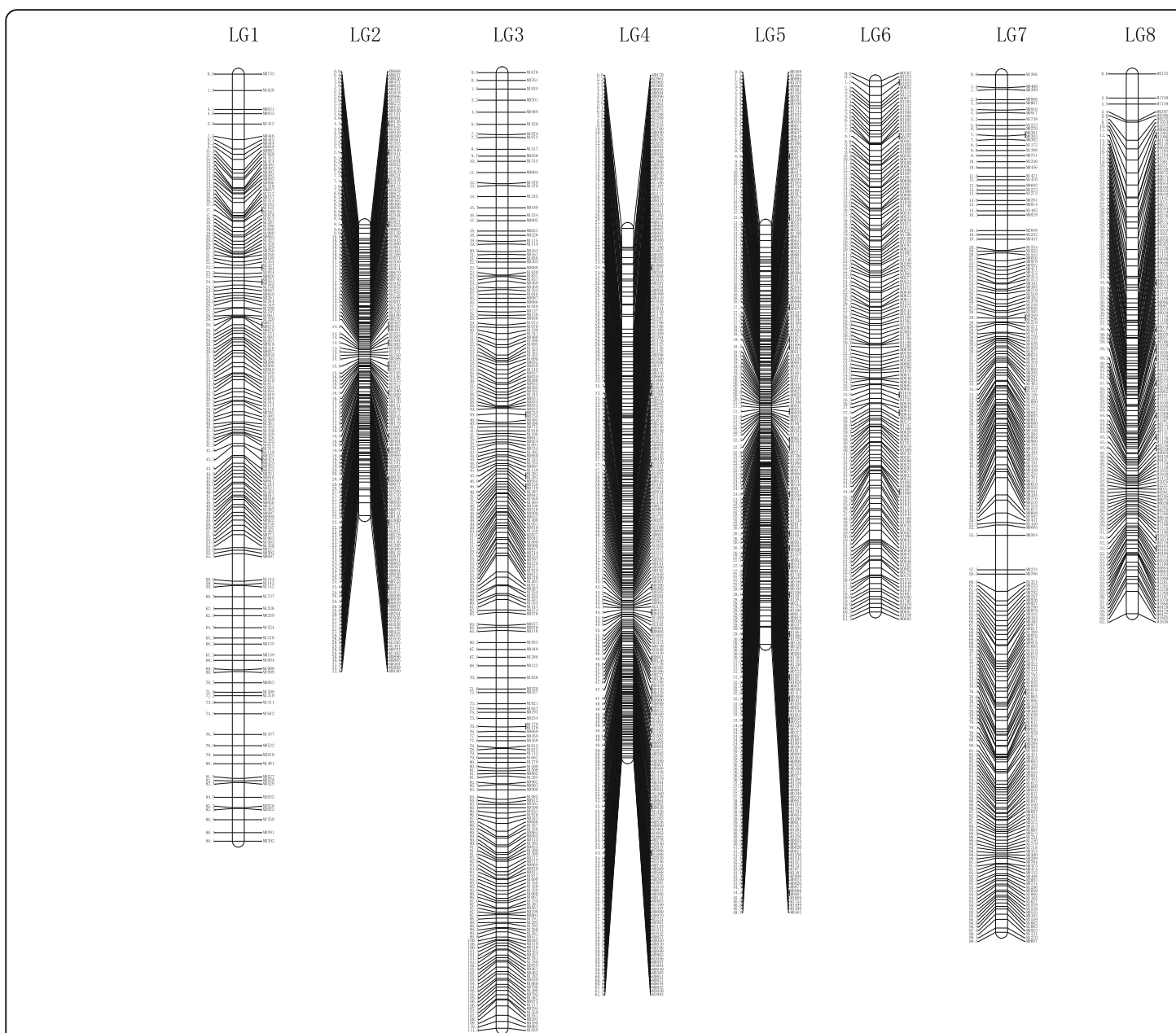

Fig. 1 The high-density genetic map of Barbarea vulgaris. Map distances based on Kosambi map units (CM) are shown on the left margin and the marker names are shown on the right margin of each linkage group

(BAR and EBAR) were evident, located at separate loci of LG5: a QTL contributing 9.4\% PVE of BAR and a QTL contributing 6.8\% PVE of EBAR, which added to the complexity of the control of these isomers. Interestingly, these two QTL of LG5 are co-localized or overlapping with QTL controlling the content of a tryptophan

Table 3 Summary statistics for the Barbarea vulgaris genetic map

\begin{tabular}{llll}
\hline Linkage Group & Number of SNP & Length (cM) & Average Gap (cM) \\
\hline LG1 & 154 & 89.082 & 0.582 \\
LG2 & 168 & 33.804 & 0.202 \\
LG3 & 219 & 110.970 & 0.509 \\
LG4 & 257 & 61.482 & 0.240 \\
LG5 & 235 & 48.659 & 0.208 \\
LG6 & 153 & 61.716 & 0.406 \\
LG7 & 213 & 99.560 & 0.470 \\
LG8 & 146 & 62.723 & 0.433 \\
Total & 1545 & 567.996 & 0.381 \\
\hline
\end{tabular}

derived glucosinolate (indole glucosinolate), the 4-methoxy derivative 4mIM. This QTL at 11.1-30.9 cM of LG5 contributed $37.2 \%$ of PVE of $4 \mathrm{mIM}$, indicating it to be the main QTL for the substituted indole glucosinolate 4mIM. Besides these overlapping loci, an additional QTL in LG4 for $4 \mathrm{mIM}$ was identified, accounting for $2.9 \%$ of the PVE. Finally, two QTL for the parent indole glucosinolate IM in LG4 and LG5 were identified, accounting for 9.2 and $16.9 \%$ of the PVE, respectively.

Overall, it was noticed that 32 of the total of 37 QTL were organized in just seven chromosome regions. In these seven regions, the QTL controlling the leaf size, color and glucosinolates were always overlapping (Fig. 3).

\section{Glucosinolate profiles in the $F_{2}$ progeny}

A considerable variation in glucosinolate profiles was observed in the $F_{2}$ progeny, and was analyzed from a biosynthetic perspective. The glucosinolates were from two biosynthetic families, the tryptophan derived (also known as indole glucosinolates: IM and 4mIM) and the 


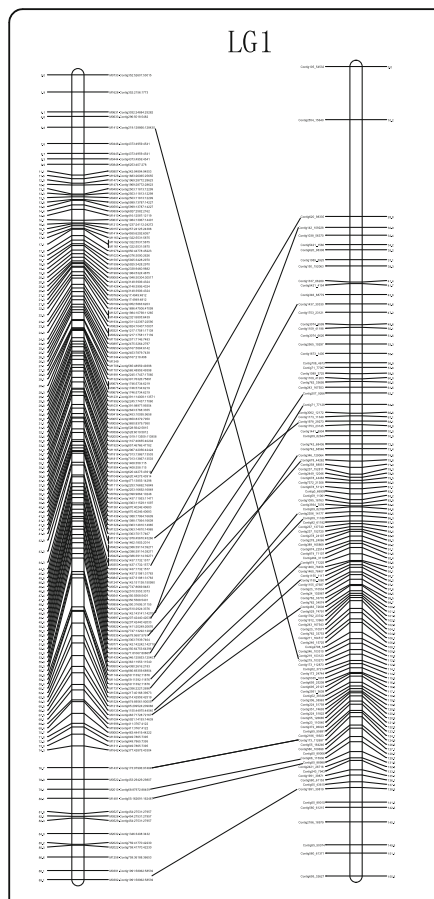

LG5

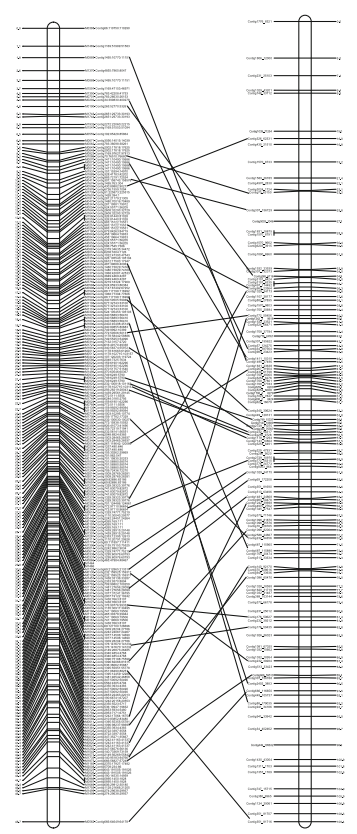

LG2

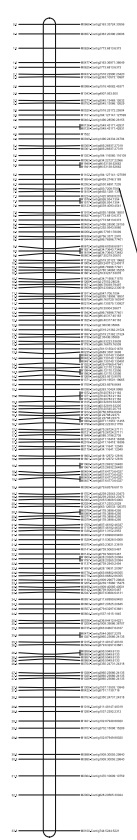

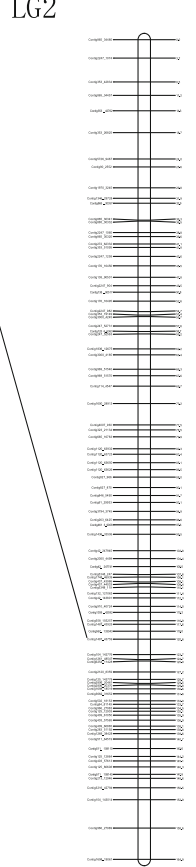

LG6

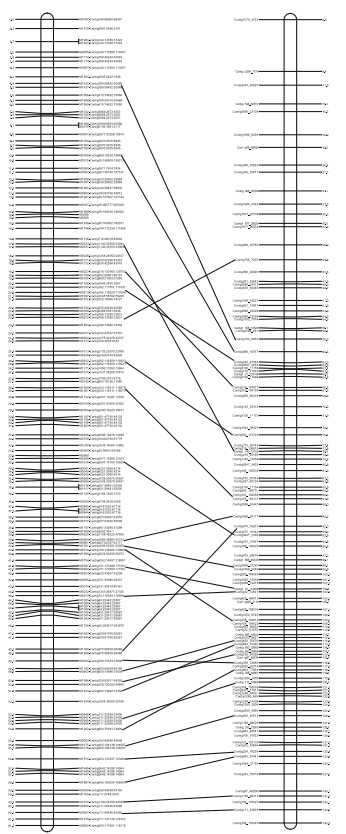

LG3

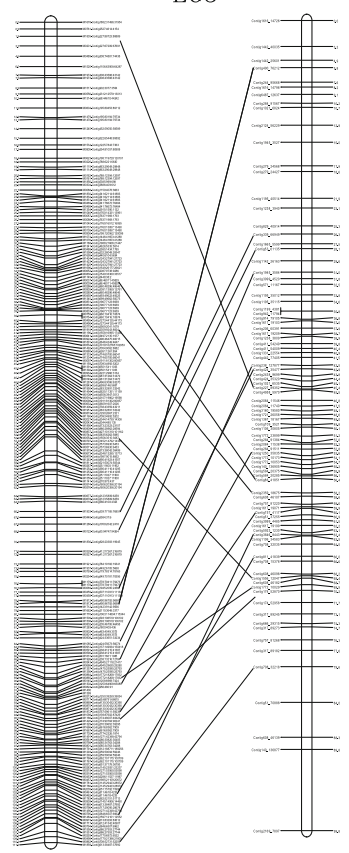

LG7
LG4

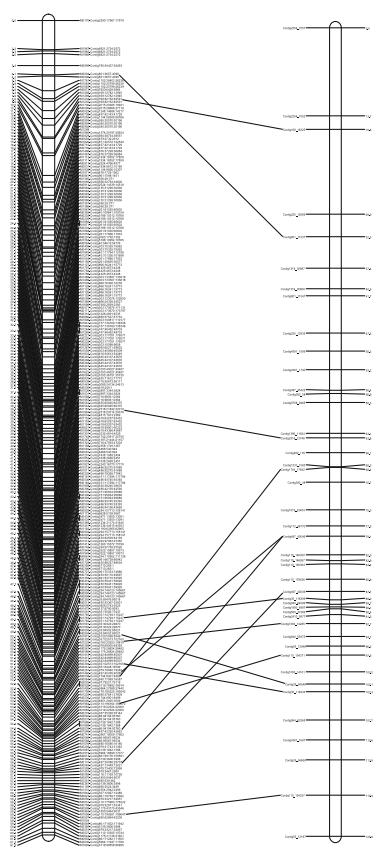

LG8
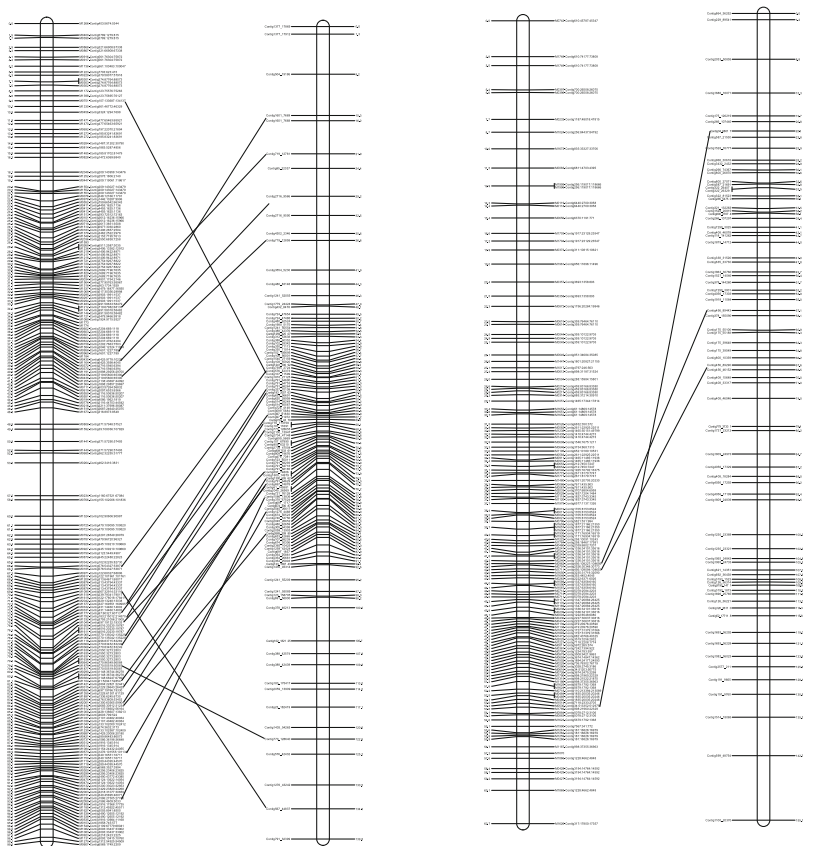

Fig. 2 Anchoring of sequenced contigs of G-type Barbarea vulgaris to the eight linkage groups and correspondence with a previously published high density linkage map. The present and previously published linkage groups are shown to the left and right, respectively. Map distances based on Kosambi map units (CM) are shown on the left margin and marker names and anchored contigs are shown on the right margin of each linkage group for the present linkage maps, while map distances are shown on the right margin and anchored contigs are shown on the left margin for the previous linkage maps. Markers that harbor the same sequenced contig are connected by a straight line between the present and previous maps

phenylalanine derived (NAS, BAR, EBAR and $p$-hydroxy derivatives of BAR and EBAR). Levels of glucosinolates from the two families were only weakly correlated
(Additional file 1: Figure S2a). In contrast to the rather similar profile of tryptophan derived glucosinolates in the two parental types, profiles of phenylalanine derived 


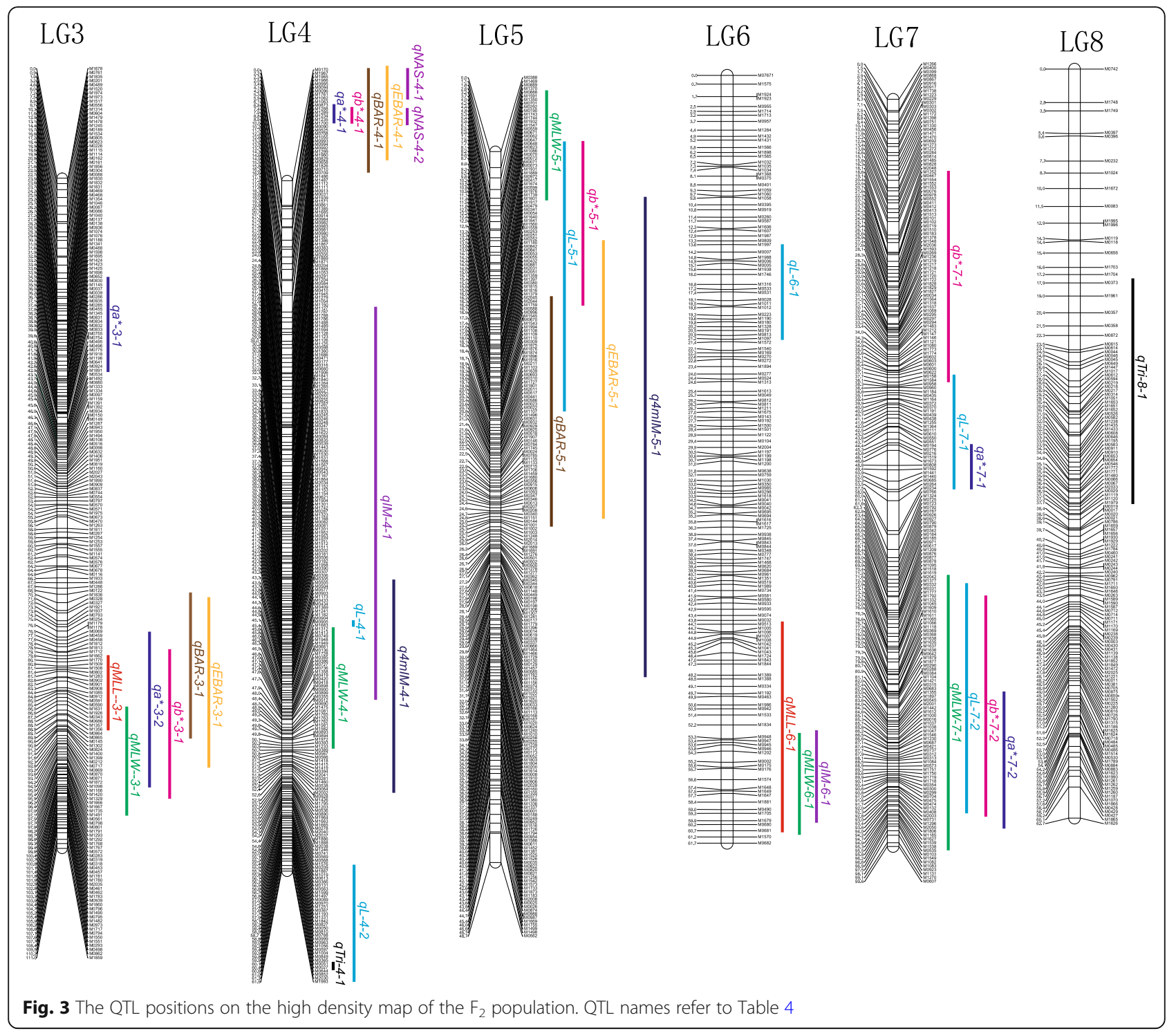

glucosinolates differed markedly, as the G-type was dominated by glucobarbarin (BAR) and the P-type was dominated by the epimer EBAR, differing solely by the stereochemistry of the 2-hydroxyl group. Despite the complex regulation of the phenylalanine derived glucosinolates (the precursor NAS and the epimeric hydroxyl derivatives BAR and EBAR), four apparent main groups of progeny could be distinguished in the glucosinolate profiles (Additional file 1: Figure S2b and c, Additional file 1: Table S3). Two of these were the parental types, the G-type like (labelled SHO rho? in Additional file 1: Figure S2b, see discussion) with BAR by far dominating over EBAR and low levels of NAS $(N=42)$, and the P-type like (labelled sho RHO? in Additional file 1 : Figure S2b), with EBAR dominating and low levels of NAS $(N=42)$ (Accidentally, the two numbers were equal). For scoring, the limit for parental types was set at less than $5 \%$ or more than $95 \%$ BAR of the combined level of BAR and EBAR, a limit in agreement with visual groups in the progeny (Additional file 1: Figure S2b). A third group with appreciable levels of both BAR and EBAR (labelled $S H O R H O$ in Additional file 1: Figure $\mathrm{S} 2 \mathrm{~b})$, was common $(N=147)$, while only very few progeny plants were observed in the fourth group (labelled sho rho in Additional file 1: Figure S2c) characterized by having high levels of the precursor phenylalanine derived glucosinolate NAS but very low levels of both BAR and EBAR $(N=8)$. Finally, a few $\mathrm{F}_{2}$ progeny plants $(N=3)$ combined a moderately high level of NAS with a high level of BAR (Additional file 1: Fig. S2c, Additional file 2: Table S3), and could hence not be unequivocally scored to any category in a simplified two gene model.

Considering the tryptophan derived glucosinolates, there was no correlation between levels of the 4-methoxy 
Table 4 QTL associated with trichome density, leaf size and color, and glucosinolates in Barbarea vulgaris rosette leaves

\begin{tabular}{|c|c|c|c|c|c|c|}
\hline Trait & Linkage Group & QTL & LOD & PVE (\%) & Intervals on maps (cM) & Additive effect \\
\hline \multirow[t]{2}{*}{ Trichome density } & 4 & qTri-4-1 & 2.5 & 4.8 & $61.0-61.5$ & -0.33 \\
\hline & 8 & qTri-8-1 & 5.8 & 14.0 & $17.4-37.6$ & -0.47 \\
\hline \multirow[t]{2}{*}{ MLL } & 3 & $9 M L L-3-1$ & 3.9 & 5.9 & $79.6-89.9$ & -0.54 \\
\hline & 6 & qMLL-6-1 & 7.9 & 19.7 & $43.8-61.0$ & -0.86 \\
\hline \multirow[t]{5}{*}{ MLW } & 3 & $9 M L W-3-1$ & 3.0 & 6.2 & $86.0-97.3$ & -0.60 \\
\hline & 4 & $q M L W-4-1$ & 3.1 & 8.7 & $45.2-50.6$ & -0.50 \\
\hline & 5 & $q M L W-5-1$ & 4.7 & 12.9 & $2.6-11.4$ & -0.63 \\
\hline & 6 & $9 M L W-6-1$ & 4.9 & 7.8 & $52.7-61.1$ & -0.21 \\
\hline & 7 & qMLW-7-1 & 2.7 & 9.4 & 71.9-95.3 & -0.61 \\
\hline \multirow[t]{6}{*}{ L } & 4 & $q L-4-1$ & 2.5 & 3.7 & $45.1-45.6$ & -0.44 \\
\hline & 4 & $q L-4-2$ & 3.5 & 4.5 & $55.6-61.5$ & -0.54 \\
\hline & 5 & $q L-5-1$ & 4.4 & 8.5 & $7.8-20.9$ & -0.65 \\
\hline & 6 & $q L-6-1$ & 3.8 & 7.5 & $13.5-21.2$ & -0.52 \\
\hline & 7 & $q L-7-1$ & 3.0 & 8.6 & $37.2-57.5$ & -0.48 \\
\hline & 7 & $q L-7-2$ & 3.0 & 6.9 & 72.9-92.3 & -0.45 \\
\hline \multirow[t]{5}{*}{$a^{*}$} & 3 & $9 a^{*}-3-1$ & 3.4 & 6.4 & $34.6-42.9$ & -0.411 \\
\hline & 3 & $9 a^{*}-3-2$ & 8.5 & 17.2 & $76.5-94.5$ & 0.60 \\
\hline & 4 & $9 a^{*}-4-1$ & 3.0 & 5.8 & $6.8-10.0$ & -0.37 \\
\hline & 7 & $q a^{*}-7-1$ & 2.6 & 5.5 & $44.4-58.0$ & 0.23 \\
\hline & 7 & $9 a^{*}-7-2$ & 5.3 & 7.9 & $83.0-90.7$ & 0.53 \\
\hline \multirow[t]{5}{*}{$b^{*}$} & 3 & $q b^{*}-3-1$ & 4.4 & 7.7 & $79.1-95.9$ & -0.86 \\
\hline & 4 & $q b^{*}-4-1$ & 3.1 & 6.2 & 7.4-9.8 & 0.63 \\
\hline & 5 & $q b^{*}-5-1$ & 4.0 & 7.7 & $7.8-16.4$ & -0.91 \\
\hline & 7 & $a b^{*}-7-1$ & 4.7 & 7.4 & $18.7-38.2$ & -0.94 \\
\hline & 7 & $9 b^{*}-7-2$ & 6.3 & 8.0 & $73.8-92.7$ & -1.11 \\
\hline \multirow[t]{2}{*}{ NAS } & 4 & qNAS-4-1 & 6.5 & 42.3 & $0.20-5.9$ & 2.71 \\
\hline & 4 & qNAS-4-2 & 4.9 & 19.3 & $7.2-10.0$ & 1.98 \\
\hline \multirow[t]{3}{*}{ BAR } & 3 & qBAR-3-1 & 23.9 & 12.5 & $68.9-89.0$ & 19.07 \\
\hline & 4 & qBAR-4-1 & 21.1 & 41.6 & $0.0-16.3$ & 26.45 \\
\hline & 5 & qBAR-5-1 & 4.6 & 9.4 & $16.2-25.2$ & -9.2 \\
\hline \multirow[t]{3}{*}{ EBAR } & 3 & qEBAR-3-1 & 10.4 & 6.4 & $71.2-93.2$ & -10.84 \\
\hline & 4 & qEBAR-4-1 & 21.6 & 71.3 & $0.0-15.0$ & -19.04 \\
\hline & 5 & qEBAR-5-1 & 7.1 & 6.8 & $13.5-24.8$ & -7.04 \\
\hline \multirow[t]{2}{*}{ IM } & 4 & $q / M-4-1$ & 7.5 & 9.2 & $28.2-48.4$ & 0.52 \\
\hline & 6 & q/M-6-1 & 5.4 & 16.9 & $52.8-60.1$ & 0.39 \\
\hline \multirow[t]{2}{*}{$4 \mathrm{mIM}$} & 4 & $94 m / M-4-1$ & 6.4 & 2.9 & $43.3-52.5$ & -0.11 \\
\hline & 5 & $q 4 m / M-5-1$ & 8.7 & 37.2 & $11.1-30.9$ & 0.11 \\
\hline
\end{tabular}

PVE, the percentage of variation explained;

Additive effect, positive additivity indicated that G-type Barbarea vulgaris carries the allele for an increase in the trait value, while negative additivity means that Ptype plants carries the allele for an increase in the trait value;

MLL, maximum leaf length; MLW, maximum leaf width;

$L$, lightness; $a^{*}$, redness and greenness and $b^{*}$, yellowness and blueness;

NAS, 2-phenylethylglucosinolate (gluconasturtiin); BAR, (2S)-2-hydroxy-2-phenylethylglucosinolate (glucobarbarin); EBAR, (2R)-2-hydroxy-2-phenylethylglucosinolate (epiglucobarbarin); IM, 3-indolylmethylglucosinolate (glucobrassicin); 4mIM, 4-methoxy-3-indolylmethylglucosinolate (4-methoxyglucobrassicin) 
derivative $4 \mathrm{mIM}$ and the precursor IM (Additional file 1: Figure S2d).

\section{Discussion}

Constructing a high-density linkage map is useful for QTL mapping [33-35], comparative genomics [36] and evolutionary biology research [37], and can even improve assembly of de novo genomic sequences [38]. In the present study, we used RAD-Seq to generate SNP markers and then constructed a high-density linkage map of B. vulgaris. A large number of markers were discarded in constructed the linkage map. There are three reasons for the discarded markers. First, the markers absent in $>15 \%$ of the total population were discarded. Among 60,287 co-dominant "aa $\times$ bb" type SNPs, only 8448 SNPs were present in at least 216 plants $(85 \%$ of the population) after filtering. Second, markers showing segregation distortion were discarded. Due to the reproductive isolation between the P-type and G-type, the segregation distortion in the $\mathrm{F}_{2}$ population is relatively high. Finally, the present marker density is approaching the limit of this technology on an $\mathrm{F}_{2}$ population with 255 individuals; adding more markers could introduce more errors and distortions. Compared with the previously published genetic maps $[1,14,30]$, the number of individuals in the $F_{2}$ population used for RAD sequencing was 2.3-fold higher, which can improve the detection of lower frequency recombination events. As far as we know, the current map represents the highest density linkage map not only for genus Barbarea but also for the crucifer tribe Cardamineae to date. This tribe contains two vegetable and condiment crops, watercress [39] and horseradish [40]. Two genomes have been published from the tribe, for Cardamine hirsuta [41] and Barbarea vulgaris [1], and the tribe is intensely studied as a case of morphological and molecular defense evolution [15, 17, 20, 30, 42-44].

In this study, we used a 1.94-fold higher number of markers achieving the capture of 722 contigs $(50.2 \mathrm{Mb}$, $30 \%$ of the assembly) (Additional file 2: Tables S1 and S2). This is significantly more than previous published maps on which only 431 contigs $(38.7 \mathrm{Mb}, 23 \%$ of the assembly) were mapped [1]. Unfortunately, the published assembly of the B. vulgaris genome has up to 7874 contigs with short length (N50 size of $14.3 \mathrm{~Kb}$ ) and only $62.1 \%(167.7 \mathrm{Mb})$ of the estimated genome $(270 \mathrm{Mb})$ was assembled into contigs [1]. Therefore, our present high-density linkage map cannot improve the genome assembly sufficiently using the existing genome sequencing data. With the rapid development of sequencing technologies, continued efforts are needed to improve the genome assembly with third generation sequencing technology.
Because the two maps used different plant populations and different suites of markers, the 150 contigs that anchored to both maps were used as bridges to match the linkage groups (pseudo chromosomes) between each other. Six out of the eight pairs of linkage groups were aligned with strong support. The LG2 and LG8 were supported by only one and three contigs respectively, not as confident as the other six LGs. However, the leaf trichome QTL was located at the LG8 in both of the two maps, suggesting alignment and numbering of the LGs to be reliable. Conflicts of contig anchoring between the two maps were observed within chromosomes and among chromosomes (Additional file 1: Figure S2 and Additional file 2: Table S1), indicating this genome to be highly complex despite its small size. One reason could be that the cruciferous plants have experienced several rounds of genome duplication. The conflicts can be due to the indistinguishable short sequences between subgenomes. Therefore, assembling longer contigs is needed to improve the genome quality.

The G- and P-types of B. vulgaris show significant morphological differences with respect to trichome density, and also show qualitative differences in glucosinolate content $[5,12,13,45]$. Visually apparent differences in leaf color and possibly leaf size has also been observed under both Chinese and Scandinavian conditions but not previously quantified or reported. In this study, a total of 37 QTL were detected for 11 different traits, each QTL explaining 2.9-71.3\% of the phenotypic variation. The previous studies on $B$. vulgaris found two QTL for trichome density, one QTL for glucobarbarin (BAR) and one QTL for the epimer epiglucobarbarin (EBAR) [1]. In the present study, these QTL were confirmed, but in addition two new QTL were detected for both BAR and EBAR. The most likely reasons for the more complex genetic model revealed in the present mapping are the enlarged population size (255 individuals of present study vs 111 individuals of previous) and the increased number of markers (1545 vs 796 markers), which improved the QTL detection efficiency $[14,46]$.

In the case of leaf trichomes, our data agree with a previous report of two QTL on LG4 and LG8 [1]. In contrast, our genetic map considerably expands the knowledge of the genetics behind a conspicuous glucosinolate polymorphism in $B$. vulgaris; the polymorphism in stereochemistry of 2-hydroxylation of NAS. The polymorphism is evident in the dominant leaf glucosinolates in the species, which are BAR and EBAR (Fig. 4). Collectively, BAR and EBAR can be called "epimeric glucobarbarins". From analysis of transcriptome [45] and genome [1] data, and comparison with glucosinolate biosynthesis in $A$. thaliana [47], it is anticipated that NAS, BAR and EBAR are all derived from the amino acid phenylalanine (via homophenylalanine), sharing the 


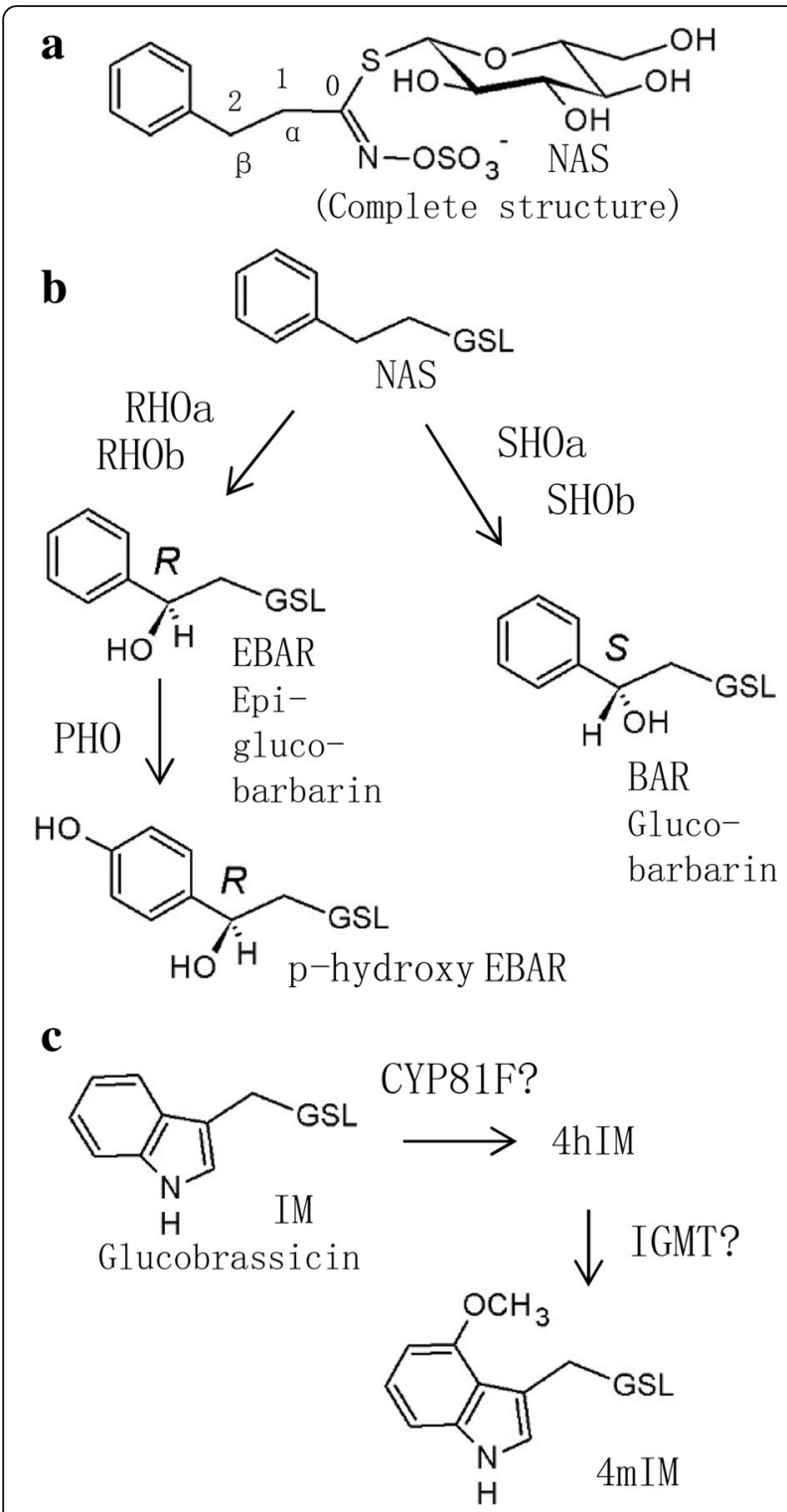

Fig. 4 Glucosinolates in Barbarea vulgaris leaves as detected in this investigation, with suggested biosynthetic relationships. a. General glucosinolate structure, using gluconasturtiin (NAS, 2phenylethylglucosinolate) as example. b. Biosynthetic relationships of phenylalanine-derived glucosinolates. The general glucosinolate biosynthesis leads to NAS, which is hydroxylated in either of two stereochemical configurations, yielding either BAR (glucobarbarin, (25)-2hydroxy-2-phenylethylGSL) or EBAR (epiglucobarbarin, (2R)-2-hydroxy-2phenylethylglucosinolate). This hydroxylation was previously anticipated to be carried out by either of two gene products, $\mathrm{SHO}$ and $\mathrm{RHO}$. Results of this work suggest involvement of several complementing gene products, provisionally named with suffixes $\mathbf{a}$ and $\mathbf{b}$. A further glucosinolate in the Ptype is $p$-hydroxy EBAR ( $p$-hydroxyepiglucobarbarin or (2R)-2-hydroxy-2-(4hydroxyphenyl)ethylglucosinolate. c. Biosynthetic relationships of tryptophanderived glucosinolates. The general indole glucosinolate biosynthesis leads to IM (glucobrassicin, indol-3-ylmethylglucosinolate). A homolog of $A$. thaliana CYP81F is expected to lead to the 4-hydroxy derivative 4hIM [38], which is probably taken to the 4-methoxy derivative $4 \mathrm{mIM}$ by a homolog of A. thaliana IGMT [60]. In all structures except the upper complete structure, the constant glucosinolate backbone is indicated as GSL general biosynthetic machinery from the amino acid precursor to the simplest of the three glucosinolates, NAS (Fig. 4). From NAS, the biosynthesis is expected to branch, catalyzed by homologs of the A. thaliana gene GS-OH (glucosinolate hydroxylation). Specifically, a homolog named SHO (S-HYDROXYLATION), which is highly expressed in the G-type but barely expressed in the P-type, was suggested to lead to BAR. In contrast, a homolog named RHO (R-HYDROXYLATION), was suggested to lead to EBAR. This model was supported by the presence of $S H O$ in a major QTL for BAR in the $B$. vulgaris genome [1]. In the previous genetic map, only one locus for BAR and one for EBAR was reported, and the loci were unlinked (with the QTL for EBAR in LG4 and the QTL for BAR in LG5) [14].

However, the simple genetic model outlined in previous reports is too simple to account for the complex genetics of epimeric glucobarbarins revealed here. From a model with just two unlinked loci, independent assortment would lead to a 1:1:1:1 ratio of four gene combinations, the parental $S H O$ rho and $R H O$ sho as well as the recombined $S H O R H O$ and sho rho. From the $\mathrm{F}_{1}$ phenotype of approximately equal levels of BAR and EBAR [45], the major genes are known to be codominant, meaning that these gene combinations would each be predictable from the phenotype, with $S H O R H O$ having relatively high levels of BAR and EBAR and sho rho having relatively low levels of BAR and EBAR, combined with high levels of NAS because of the still ongoing general glucosinolate biosynthesis leading to accumulation of the precursor of BAR and EBAR. The observation of a high proportion of recombinant progeny was in agreement with several genetic models, however, the low frequency $(5.6 \%$ or $7.7 \%$ depending on interpretation of glucosinolate profiles) of apparent sho rho progeny plants, with low levels of both BAR and EBAR combined with a high level of NAS, was in disagreement with a model of two unlinked genetic loci of $\mathrm{SHO} /$ sho and $R H O / r h o$. The same unexpected deficiency in offspring dominated by NAS had also been reported from the first B. vulgaris map but not discussed [14].

The present discovery of multiple QTL for the epimeric glucobarbarins (BAR and EBAR), in combination with the recently published genome, provides a potential explanation of these consistent recombination proportions. Investigation of the genome revealed three different genes in the G-type with sequence similarity to GS-OH, named GS-OH-like $1,-2$ and -3 . Of these, GS-OH-like 1 was found identical to $\mathrm{SHO}$ and had an allele with very low expression in the P-type (sho) [1]. The number of homologs in the P-type was not determined with certainty. Assuming several GS-OH like genes in each type of $B$. vulgaris, the dominance of progeny plants high in both BAR and EBAR, and the 
scarcity of progeny plants low in both epimeric glucobarbarins and high in NAS, can be explained. Obvious fine structure in the group observations attributed to SHO RHO (Additional file 1: Figure S2b) is likewise in accordance with the suggested complex genetic model. In this biosynthetic/genetic model (Fig. 4), this suggestion is illustrated with additional homologs of $\mathrm{SHO}$ and/ or $R H O$, provisionally named with suffixes a and $\mathrm{b}$ (etc.). However, despite the added complexity from additional loci for 2-hydroxylation, we suggest that some sho rho progeny plants were correctly identified from glucosinolate profiles (Additional file 1: Figure S2c), while some progeny plants of more complex recombinant genotypes (e.g. of the type sho a SHO $b$ / - -) may have appeared like the parental types or $S H O R H O$ types in Additional file 1: Figure S2b. A combination of sho rho with compensatory "SHOb" genes with intermediate penetrance could lead to the three atypical plants with appreciable levels of both NAS and BAR, as well as numerous progeny plants with slightly above normal levels of NAS (Additional file 1: Figure S2c). According to this hypothesis, the QTL for BAR and EBAR in LG3, LG4 (and possibly LG5, see below) would be due to homologs of GS-OH or any other gene family encoding hydroxylating enzymes. Indeed, it is currently not certain whether $\beta$-hydroxylation of glucosinolates generally occurs via GS-OH enzymes, and whether single alleles of GS-OH in Arabidopsis and Brassica are a result of convergent evolution [48]. Hydroxylation of glucosinolate side chains is of huge economic importance, being critical for the nutritional value of many vegetables and industrial crops [49], and a better understanding of its biochemistry can influence breeding in many species.

Considering indole glucosinolates (IM and 4mIM, Fig. 4), the genetics and biochemistry in A. thaliana is increasingly well understood [50,51]. No qualitative or quantitative difference of $4 \mathrm{mIM}$ between the two B. vulgaris types was realized before this investigation [13]. Assuming similarity to A. thaliana [45], any specific QTL for 4mIM could represent the first hydroxylation step (CYP81F) or the second methylation step (a homolog of IGMT) or a regulatory locus (Fig. 4c). However, because of possible overlap of QTL for 4mIM, BAR and EBAR on LG5 and of IM and 4IM on LG4, the loci could also represent more general control of glucosinolate biosynthesis, so speculation on the nature of these possibly overlapping loci would seem premature.

A further glucosinolate in the P-type is the para-hydroxyl derivative of EBAR (Fig. 4), which gives rise to a unique type of hydrolysis product [12]. In $F_{1}$ progeny and other plants with high levels of BAR, EBAR and even NAS, para-hydroxyl derivatives of the dominating glucosinolates accumulate, suggesting a gene for parahydroxylation of phenylalanine derived glucosinolates in general. To our surprise, no QTL was detected for $p$-hydroxy derivatives of epimeric glucobarbarins (Fig. 4). Lack of detection of this expected QTL could be due to the very low levels of $p$-hydroxyls observed in our progeny plants, which may lead to analytical inaccuracy due to possible peak overlap with impurities.

The content of NAS in the crop watercress is well established. More recently, it was reported that many commercial accessions from the USA also contain epimeric glucobarbarins, which are of unknown nutritional and toxicological importance [52]. Molecular data for watercress are accumulating [52-55], but high quality genetic maps are yet lacking. As Barbarea and watercress are related [40] and share the same basic chromosome number $(n=8)$, the present high-density map may be of relevance also for watercress breeding.

The observed glucosinolate profiles mirror characteristic variation known from within-plant differences and from natural populations. While relative levels of EBAR and BAR are highly skewed in leaves, they are typically less skewed in roots [13] and in seeds of some accession [12], all in accordance with a model of several homologs that could vary in tissue-specific expression. In nature, the G-type and P-type of B. vulgaris occupy separate geographic areas, with a meeting zone somewhere in Eastern/Central Europe [4]. Indeed, near that meeting zone apparent hybrid populations were detected [13]. One such hybrid population from Finland showed $F_{1}$ like glucosinolate profiles, while a population from Slovenia contained a high proportion of individuals dominated by NAS ("NAS-forms"). In another population, from the Caucasus, individuals with high proportions of both NAS and EBAR (and further peculiarities) were observed, reminiscent of the rare phenotypes high in both NAS and BAR observed in $F_{2}$ progeny. The present work provides an explanation of how these aberrant phenotypes could have originated from $\mathrm{P} \times \mathrm{G}$ type hybridization and genetic recombination, and confirms creation of such new glucosinolate profiles by controlled hybridisation. Similar aberrant phenotypes have been reported from the Netherlands [56], far from the meeting zone of the types, and were found to correlate with marked ecological effects [57], although a causal relationship has recently been questioned [58].

To the best of our knowledge, this is the first report of QTL for leaf size, leaf color, gluconasturtiin (NAS) and indole glucosinolates of $B$. vulgaris rosette leaves. In addition, our analysis provides further details on the genetic regulation of epimeric glucobarbarins, the dominating glucosinolates in the parental types. Interestingly, most of the QTL were overlapping and enriched at seven chromosome regions. For example, the QTL regions for maximum leaf length and width, $\mathrm{L}, \mathrm{a}^{*}$ and $\mathrm{b}^{*}$ are overlapped on LG3, LG5, and LG7. This can be 
explained by assuming that $\mathrm{L}$, $\mathrm{a}^{*}$ and $\mathrm{b}^{*}$ are representations of components of photosynthetic pigments which directly controls the photosynthesis and therefore affect leaf size. However, we had not anticipated the QTL for glucosinolates to be co-localized with those of leaf size and color components. This finding will impel us to recognize the relationship between the secondary metabolism and plant development. However, a role of glucosinolates in plant growth regulation is currently being unravelled in A. thaliana [59], so an effect of glucosinolate biosynthetic genes on general plant growth parameters is not unlikely. Fine-mapping of these QTL by enlarging the mapping population and finally cloning of the genes using improved genome sequences would be worth doing in the future.

\section{Conclusions}

In conclusion, the present study reports the highest density linkage map to date for the crucifer tribe Cardamineae. On the basis of the present high-density genetic map, an improvement of genome contigs was anchored compared to a previously published map. Besides, 37 QTL were detected for eleven traits of glucosinolates, leaf size and color, each QTL explaining $2.9-71.3 \%$ of the phenotype variation. The QTL obtained in this study will be useful for further understanding the molecular genetic basis of these traits, many of which are shared in the related crop watercress.

\section{Methods}

\section{Plant material and cultivation}

Seeds of B. vulgaris accessions B4 (P-type, NGB23547) and B44 (G-type, NGB31789) and $F_{1}$ hybrid were obtained as previously reported [45]. Both accessions are available from www.nordgen.org/sesto and registered under the indicated NGB numbers. The $255 \mathrm{~F}_{2}$ individuals in the mapping population were generated from self-pollination of a single $F_{1}$ plant. All plants were grown in the Institute of Vegetables and Flowers, Chinese Academy of Agricultural Sciences, China, an area having freezing winters and hot summers. Seeds of the $\mathrm{F}_{2}$ generation were surface sterilized in $1 \% \mathrm{NaClO}$ and sown in $9 \times 9 \mathrm{~cm}$ pots filled with a mixture of peat and vermiculite $(\mathrm{V}: \mathrm{V}=2: 1)$ on March 5, 2015. Plants were kept in a growth chamber until transplant atconditions as in our previous report [45]. The seedlings were transplanted to a plastic tunnel with a row spacing of $50 \mathrm{~cm}$ and a plant spacing of $30 \mathrm{~cm}$ on April 30. Plants were given fertilizer and water as needed.

\section{Genomic DNA extraction}

Young leaves of $\mathrm{F}_{2}$ plants and their parents were collected, freeze-dried and ground to a fine powder. Genomic DNA was extracted from $100 \mathrm{mg}$ leaf sample for each plant using the CTAB method [60]. The quality of the DNA was assessed by $1 \%$ agarose gel electrophoresis and Nano Photometer (TIMPLEN,CA, USA), and the concentrations were measured by a Qubit ${ }^{\circ}$ DNA Assay Kit in a Qubit $^{\circ}$ 2.0 Fluorimeter (Life Technologies, CA, USA).

\section{RAD-Seq library construction and Illumina sequencing}

The RAD-Seq libraries were constructed according to the protocol of Baird et al. [33]. The restriction enzyme EcoR I was used to digest genomic DNA and P1 adapter (contains forward amplification and Illumina sequencing primer sites, as well as a nucleotide barcode $6 \mathrm{bp}$ long for sample identification) was ligated to the fragment's compatible ends. The adapter-ligated fragments were subsequently polled, randomly sheared, and size-selected. Then, the fragments were ligated to a P2 adapter, a Y adapter that has divergent ends. PCR amplification was conducted and DNA fragments spanning 200-600 bp were isolated on a $1 \%$ agarose gel and purified for library construction. The qualities of the libraries were ensured, and then paired-end (150 bp) sequencing was carried out on an Illumina HiSeq platform.

\section{RAD-Seq sequence analyses and SNP markers development}

Raw sequence reads of '.fastq' format were segregated by the barcode assigned to each sample and filtered to remove low-quality sequences and trimmed adaptor. Reads with ambiguous ' $N$ ' nucleotides exceeding $10 \%$ of read length were eliminated. Sequences in which more than $50 \%$ of the nucleotides had a Phred score below 5 were also considered low quality and eliminated. The trimmed reads of G-type and P-type B. vulgaris were clustered based on sequence similarity using the cd-hit-test with parameters of less than 3 nucleotides mismatch [61]. Clusters with read depth very low (less than 10) or very high (more than 400) were excluded.

The paired-end reads of each cluster passing the above tests were then subjected to de novo assembly to generate contigs using the VelvetOptimizer [62] with parameters of "VelvetOptimiser.pl -s 23 -e 31 -x 4". Contigs less than $125 \mathrm{bp}$ were discarded. The remainder of the contigs were used as reference genome for other analysis. Sequencing reads were aligned to the reference genome using BWA software (settings: mem $-\mathrm{t} 4-\mathrm{k} \quad 32-\mathrm{M}$ ). Alignment files were converted to BAM files using SAM tools software [63]. Variant allele calling was performed for each individual by using the mpileup function in SAM tools (settings: mpileup -q 1 -C 50 -S -D -m 2 -F 0.002) [64]. Polymorphic contigs in the G-type and P-type $B$. vulgaris were identified by the presence of at least 10 reads in one type and none in the other [65]. 
Polymorphic reads were mapped to the P-type (reference sequence) first to identify perfect matches as RAD marker sites and then searched for SNPs [33]. The types of SNPs in individual $F_{2}$ progeny were identified by the presence of at least 4 but no more than 1000 reads.

\section{Linkage map construction}

RAD markers genotyped with more than $15 \%$ missing data in the $F_{2}$ progeny were removed. The marker segregation frequencies were determined using chi-squared analysis to test the goodness of fit to the expected segregation ratio of 1:2:1. Markers showing significant segregation distortion at $P<0.001$ were excluded in the present study [66]. JoinMap 4.0 was used for recombination calculation and the genetic map construction [67]. After having removed the similar sites (similarity $>0.95$ ), the remaining markers were divided into eight groups and the marker order of each linkage group was ordered using the regression mapping algorithm of JoinMap 4.0. The severely unlinked markers were discarded and the MapChart program was used to visualize exported maps [68].

\section{Alignment of linkage groups with the contigs and synteny block with previous genome sequencing}

To keep the correspondence of our present linkage groups with the eight $B$. vulgaris chromosomes, we aligned our high density genetic map with the contigs (http://plen.ku.dk/Barbarea) generated by genome sequencing of G-type B. vulgaris using a Perl script. Furthermore, the visualized map of corresponding markers of the two high-density linkage maps were generated based on the commonly harbored contigs.

\section{Phenotyping and QTL detection}

Forty-one days after transplanting (June 10, 2015), the trichome density of the youngest and four additional randomly selected true leaves was scored on a $0-4$ scale [4] with a little modification: $0=$ no trichomes; $1=$ few, occasional trichomes on leaf margin; $2=$ several trichomes on leaf margin and veins, but none on lamina; $3=$ many trichomes, also on lamina, but significantly less than P-type plants; 4 = many trichome, also on lamina, similar to or surpassing the P-type. For each of the $F_{2}$ individuals, the largest leaf was selected and pressed flat on a surface to measure the end-lobe by a ruler, thereby determining the maximum leaf length $(\mathrm{cm})$ and maximum leaf width $(\mathrm{cm})$ at 30 days after transplanting. The leaf colors were observed by a CR-400 color difference meter (Konica Minolta, Shanghai, China) and three randomly selected true leaves per plant were measured. The leaf color was presented according to CIE 1976 Lab standards [69] by L (lightness), a* (redness and greenness) and b* (yellowness and blueness) with a standard D65 light source. For glucosinolate analysis, four true leaves (including petiole and side lobes) among those of intermediate developmental stage of each $\mathrm{F}_{2}$ individual were randomly sampled on July 20,2015 . The leaf samples were freeze-dried at $-80^{\circ} \mathrm{C}$ and then ground into a fine powder. Two hundred $\mathrm{mg}$ of leaf powder was used for glucosinolate analysis by HPLC of desulfated derivatives as in our previous report [45].

Putative QTL location was determined by the composite interval mapping (CIM) method using winQTLcart [70]. The phenotypic variance explained (PVE), as well as additive genetic effects and intervals on maps by each QTL were obtained. The LOD score threshold $(\alpha=0.05)$ for determining the presence of a QTL was calculated using the permutation test (1000 replications) [71].

\section{Additional files}

Additional file 1: Figure S1. The number and coverage of RAD-tags for $\mathrm{G}$-type, $\mathrm{P}$-type and each $\mathrm{F}_{2}$ individual of Barbarea vulgaris. The $\mathrm{x}$-axis indicates the plant accession including G-type, P-type and each of the $F_{2}$ individuals; the $y$-axis indicates the number of RAD-tags (a) and the coverage (b). Figure S2. Characteristics of the glucosinolate profiles in $F_{2}$ offspring from a cross between P-type and G-type B. vulgaris. a. Glucosinolates from each of the two biosynthetic families, tryptophan (Trp) derived and phenylalanine (Phe) derived, showed little correlation. b. Three large, rather well defined groups of progeny plants could be recognized from the balance of the glucosinolate epimers BAR and EBAR. For the inserted hypothetic genotypes, see Discussion. The question marks indicate that the genotypes may be overly simplified, due to additional genes influencing the glucosinolate profile. In addition, a further fine structure in the group SHO RHO is evident, with one group (the upper) relatively higher in EBAR than the other. C. A plot of NAS levels as a function of the sum of its two hydroxyl derivatives BAR and EBAR revealed a small deviating group of 'NAS-form' progeny plants, characterized by very low levels of both epimeric glucobarbarins (BAR and EBAR), resulting in accumulation of the apparent biosynthetic precursor, NAS. Reasons for the very low number of apparent sho rho plants are discussed in Discussion. d. Levels of the 4substituted indole glucosinolate $4 \mathrm{mIM}$ were essentially not correlated with the precursor IM, suggesting the substitution to be specifically regulated, in agreement with identification of a major QTL for $4 \mathrm{mIM}$ (ZIP 238 kb)

Additional file 2: Table S1. Anchoring of sequenced contigs of G-type Barbarea vulgaris to the eight linkage groups. Table S2. Comparison of anchored contig information between this and the best previous Barbarea vulgaris genome assembly. Table S3. The trichome density, color, maximum leaf length and width, and glucosinolate content in the leaves of each individual of the $F_{2}$ population of Barbarea vulgaris (ZIP $1442 \mathrm{~kb}$ )

\section{Abbreviations \\ 4mIM: 4-methoxy-3-indolylmethylglucosinolate (4-methoxyglucobrassicin); $a^{*}$ : Redness and greenness; AFLP: Amplified fragment length polymorphism; $b^{*}$ : Yellowness and blueness; BAR: (2S)-2-hydroxy-2-phenylethylglucosinolate (glucobarbarin); CIM: Composite interval mapping; CTAB: Cetyl trimethyl ammonium bromide; EBAR: (2R)-2-hydroxy-2-phenylethylglucosinolate (epiglucobarbarin); GS-OH: Glucosinolate hydroxylation; G-type: Glabrous type; HPLC: High performance liquid chromatograph; IM: 3- \\ indolylmethylglucosinolate (glucobrassicin); L: Lightness; LG: Linkage group; MLL: Maximum leaf length; MLW: Maximum leaf width; NAS: 2- phenylethylglucosinolate (gluconasturtiin); P-type: Pubescent type; PVE: Phenotypic variation; QTL: Quantitative trait locus; RAD-Seq: Restriction site-associated DNA sequencing; RHO: R-HYDROXYLATION; SHO: S- HYDROXYLATION; SNP: Single nucleotide polymorphism; SSR: Simple sequence repeat}

\section{Acknowledgements}

We thank Dr. Dan Kliebenstein for discussions and Dr. Allison M. Heskes for English language editing. 


\section{Funding}

This work was supported by grant from the National Key Technology R \& D Program of the Ministry of Science and Technology of China (2013BAD01B042), Agriculture Research System of the Ministry of Agriculture and Rural Affairs of China (CARS-24-A-01), Henan Provincial Science and Technology Open Cooperation Project of the Department of Science and Technology of Henan Province (182106000052). These findings supported in the design of the study and collection, analysis, and interpretation of data and in writing the manuscript.

\section{Availability of data and materials}

Sequences data generated in this study are available on the Sequence Read Archive http://www.ncbi.nlm.nih.gov/Traces/sra/, at accession SRP144589.

\section{Authors' contributions}

$X L, T L$ and $X H Z$ designed and conceived the experiments; $T L, J S, Y Q, H W$ and XW performed the experiments; JS and XW participated in plant material growth and experiments; $\mathrm{HH}$ and $\mathrm{XZZ}$ have taken part in glucosinolate analysis; $T L, X H Z, N A, X L$ analyzed the data; $T L, X H Z, X L, N A$ and $Y Z$ wrote the manuscript. All authors read and approved the final manuscript.

\section{Ethics approval and consent to participate}

Not applicable

\section{Consent for publication}

Not applicable

\section{Competing interests}

The authors declare that they have no competing interests.

\section{Publisher's Note}

Springer Nature remains neutral with regard to jurisdictional claims in published maps and institutional affiliations.

\section{Author details}

${ }^{1}$ Institute of Vegetables and Flowers, Chinese Academy of Agricultural Sciences; Key Laboratory of Biology and Genetic Improvement of Horticultural Crops, Ministry of Agriculture, Beijing 100081, China. ${ }^{2}$ Copenhagen Plant Science Center and Department of Plant and Environmental Sciences, University of Copenhagen, Thorvaldsensvej 40, 1871 Frederiksberg C, Denmark. ${ }^{3}$ Henan Academy of Agricultural Sciences, Institute of Horticulture, Zhengzhou 450002, China. ${ }^{4}$ Vegetable Research Center, Beijing Academy of Agriculture and Forestry Sciences, Beijing 100097, China.

Received: 14 October 2018 Accepted: 3 May 2019

Published online: 14 May 2019

\section{References}

1. Byrne SL, Erthmann P $\varnothing$, Agerbirk N, Bak S, Hauser TP, Nagy I, Paina C, Asp T. The genome sequence of Barbarea vulgaris facilitates the study of ecological biochemistry. Sci Rep. 2017;7:40728. https://doi.org/10.1038/ srep40728.

2. MacDonald MA, Cavers PB. The biology of Canadian weeds. 97. Barbarea vulgaris R. Br. Can J Plant Sci. 1991;71:149-66.

3. Nielsen JK. Variation in defences of the plant Barbarea vulgaris and in counteradaptations by the flea beetle Phyllotreta nemorum. Entomol Exp Appl. 1997:82:25-35.

4. Christensen S, Heimes C, Agerbirk N, Kuzina V, Olsen CE, Hauser TP. Different geographical distributions of two chemotypes of Barbarea vulgaris that differ in resistance to insects and a pathogen. J Chem Ecol. 2014;40: 491-501.

5. Liu TJ, Zhang XH, Li XX, Shen D, Wang HP, Qiu Y, et al. Advances on research and utilization of elite resistant resource-Barbarea vulgris. Acta Hortic Sin. 2015;42:1719-31.

6. Agerbirk N, Olsen CE, Bibby BM, Frandsen HO, Brown LD, Nielsen JK, et al. A saponin correlated with variable resistance of Barbarea vulgaris to the diamondback moth Plutella xylostella. J Chem Ecol. 2003:29:1417-33.

7. Liu TJ, Zhang XH, Shen D, Wang HP, Qiu Y, Song JP, et al. Analysis on genetic diversity of Barbarea vulgris germplasm resources based on phenotypic traits. J Plant Genetic Resour. 2015;16:528-34.
8. Badenes-Pérez FR, López-Pérez JA. Resistance and susceptibility to powdery mildew, root-knot nematode, and western flower thrips in two types of winter cress (Brassicaceae). Crop Prot. 2018;110:41-7.

9. Christensen S, Enge S, Jensen KR, Müller C, Kiær LP, Agerbirk N, et al. Different herbivore responses to two co-occurring chemotypes of the wild crucifer Barbarea vulgaris. Arthropod Plant Interact. 2019;13:19-30 https://doi.org/10.1007/s11829-018-9633-x.

10. Van Molken T, Heimes C, Hauser TP, Sundelin T. Phylogeny of an Albugo sp. infecting Barbarea vulgaris in Denmark and its frequency of symptom development in natural populations of two evolutionary divergent plant types. Fungal Biol. 2014;118:340-7.

11. Dalby-Brown L, Olsen CE, Nielsen JK, Agerbirk N. Polymorphism for novel tetraglycosylated flavonols in an eco-model crucifer, Barbarea vulgaris. J Agr Food Chem. 2011;59:6947-56.

12. Agerbirk N, Olsen CE. Glucosinolate hydrolysis products in the crucifer Barbarea vulgaris include a thiazolidine-2-one from a specific phenolic isomer as well as oxazolidine-2-thiones. Phytochemistry. 2015;115:143-51.

13. Agerbirk N, Olsen CE, Heimes C, Christensen S, Bak S, Hauser TP. Multiple hydroxyphenethyl glucosinolate isomers and their tandem mass spectrometric distinction in a geographically structured polymorphism in the crucifer Barbarea vulgaris. Phytochemistry. 2015;115:130-42.

14. Kuzina V, Nielsen JK, Augustin JM, Torp AM, Bak S, Andersen SB. Barbarea vulgaris linkage map and quantitative trait loci for saponins, glucosinolates, hairiness and resistance to the herbivore Phyllotreta nemorum. Phytochemistry. 2011;72:188-98.

15. Zhang XH, Liu TJ, Wei XC, Qiu Y, Song JP, Wang HP, et al. Expression patterns, molecular markers and genetic diversity of insect-susceptible and resistant Barbarea genotypes by comparative transcriptome analysis. BMC Genomics. 2015;16(486) https://doi.org/10.1186/s12864-015-1609-y.

16. Shinoda T, Nagao T, Nakayama M, Serizawa H, Koshioka M, Okabe H, et al. Identification of a triterpenoid saponin from a crucifer, Barbarea vulgaris, as a feeding deterrent to the diamondback moth, Plutella xylostella. J Chem Ecol. 2002;28:587-99.

17. Erthmann $P \varnothing$, Agerbirk N, Bak S. A tandem array of UDP-glycosyltransferases from the UGT73C subfamily glycosylate sapogenins, forming a spectrum of mono- and bisdesmosidic saponins. Plant Mol Biol. 2018:97:1-19.

18. Nielsen JK, Nagao T, Okabe H, Shinoda T. Resistance in the plant, Barbarea vulgaris, and counter-adaptations in flea beetles mediated by saponins. J Chem Ecol. 2010;36:277-85.

19. Pedras $\mathrm{M}, \mathrm{To} \mathrm{QH}$. Synthesis of stable isotope-labeled nasturlexins and potential precursors to probe biosynthetic pathways of cruciferous phytoalexins. J Labelled Compd Rad. 2018;61:94-106.

20. Pedras MSC, Mahla A, To QH. Expanding the nasturlexin family: Nasturlexins $C$ and $D$ and their sulfoxides are phytoalexins of the crucifers Barbarea vulgaris and B. verna. Phytochemistry. 2015;118:131-8.

21. Lu JH, Liu SS, Shelton AM. Laboratory evaluations of a wild crucifer Barbarea vulgaris as a management tool for the diamondback moth Plutella xylostella (Lepidoptera: Plutellidae). B Entomol Res. 2004;94:509-16.

22. Badenes-Perez FR, Reichelt M, Heckel DG. Can sulfur fertilisation improve the effectiveness of trap crops for diamondback moth, Plutella xylostella (L.) (Lepidoptera: Plutellidae)? Pest Manag Sci. 2010;66:832-8.

23. Badenes-Perez FR, Shelton AM, Nault BA. Using yellow rocket as a trap crop for diamondback moth (Lepidoptera: Plutellidae). J Econ Entomol. 2005;98: 884-90.

24. Fahleson J, Eriksson I, Glimelius K. Intertribal somatic hybrids between Brassica napus and Barbarea vulgaris - production of in vitro plantlets. Plant Cell Rep. 1994;13:411-6.

25. Ravanfar SA, Aziz MA, Saud HM, Abdullah JO. Optimization of in vitro regeneration and Agrobacterium tumefaciens-mediated transformation with heat-resistant cDNA in Brassica oleracea subsp italica cv. Green marvel. Curr Genet. 2015;61:653-63.

26. Song GQ, Walworth AE, Hancock JF. Agrobacterium tumefaciens-mediated transformation of rutabaga (Brassica napus var. napobrassica) cultivar "American purple top yellow". In Vitro Cell Dev-PI. 2012;48:383-9.

27. Bhalla PL, Singh MB. Agrobacterium-mediated transformation of Brassica napus and Brassica oleracea. Nat Protoc. 2008;3:181-9.

28. Lander ES, Botstein D. Mapping mendelian factors underlying quantitative traits using RFLP linkage maps. Genetics. 1989;121:185-99.

29. Ørgaard M, Linde-Laursen I. Cytogenetics of Danish species of Barbarea (Brassicaceae): chromocentres, chromosomes and rDNA sites. Hereditas. 2007;144:159-70. 
30. Khakimov B, Kuzina V, Erthmann PØ, Fukushima EO, Augustin JM, Olsen CE, et al. Identification and genome organization of saponin pathway genes from a wild crucifer, and their use for transient production of saponins in Nicotiana benthamiana. The Plant J. 2015;84:478-90.

31. Zhang Z, Wei T, Zhong Y, Li X, Huang J. Construction of a high-density genetic map of Ziziphus jujuba mill. Using genotyping by sequencing technology. Tree Genet Genomes. 2016;12:76.

32. Davey JW, Hohenlohe PA, Etter PD, Boone JQ, Catchen JM, Blaxter ML. Genome-wide genetic marker discovery and genotyping using nextgeneration sequencing. Nat Rev Genet. 2011;12:499-510.

33. Baird NA, Etter PD, Atwood TS, Currey MC, Shiver AL, Lewis ZA. Rapid SNP discovery and genetic mapping using sequenced RAD markers. PLoS One. 2008;3(10):e3376 https://doi.org/10.1371/journal.pone.0003376.

34. Barchi L, Lanteri S, Portis E, Valè G, Volante A, Pulcini L. A RAD tag derived marker based eggplant linkage map and the location of QTLs determining anthocyanin pigmentation. PLoS One. 2012;7(8):e43740 https://doi.org/10. 1371/journal.pone.0043740.

35. Jiang B, Liu W, Xie D, Peng Q, He X, Ye L, et al. High-density genetic map construction and gene mapping of pericarp color in wax gourd using specific-locus amplified fragment (SLAF) sequencing. BMC Genomics. 2015;16(1035) https://doi.org/10.1186/s12864-015-2220-y.

36. Wang F, Singh R, Genovesi AD, Wai CM, Huang X, Chandra A. Sequencetagged high-density genetic maps of Zoysia japonica provide insights into genome evolution in Chloridoideae. Plant J. 2015;82:744-57.

37. Nietlisbach P, Camenisch G, Bucher T, Slate J, Keller LF, Postma E. A microsatellite-based linkage map for song sparrows (Melospiza melodia). Mol Ecol Resour. 2015;15:1486-96.

38. Glazer AM, Killingbeck EE, Mitros T, Rokhsar DS, Miller CT. Genome assembly improvement and mapping convergently evolved skeletal traits in sticklebacks with genotyping-by-sequencing, G3. Genes Genom Genet. 2016;5:1463-72.

39. Payne AC, Clarkson GJJ, Rothwell S, Taylor G. Diversity in global gene expression and morphology across a watercress (Nasturtium officinale R. Br.) germplasm collection: first steps to breeding. Hortic Res. 2015;2(15029) https://doi.org/10.1038/hortres.2015.29.

40. Mandáková T, Lysak MA. Healthy roots and leaves: comparative genome structure of horseradish and watercress. Plant Physiol. 2019;179:66-73.

41. Gan XC, Hay A, Kwantes M, Haberer G, Hallab A, loio RD, et al. The Cardamine hirsuta genome offers insight into the evolution of morphlogical diversity. Nat Plants. 2016;2:16167. https://doi.org/10.1038/ NPLANTS.2016.167.

42. Hay AS, Pieper B, Cooke E, Mandáková T, Cartolano M, Tattersall AD, et al. Cardamine hirsuta: a versatile genetic system for comparative studies. Plant J. 2014;78:1-15.

43. Bakhtiari M, Glauser G, Rasmann S. Root JA induction modifies glucosinolate profiles and increases subsequent aboveground resistance to herbivore attack in Cardamine hirsuta. Front Plant Sci. 2018;9:1230. https://doi.org/10. 3389/fpls.2018.01230.

44. Olsen CE, Huang XC, Hansen CIC, Cipollini D, Ørgaard M, Matthes A, et al. Glucosinolate diversity within a phylogenetic framework of the tribe Cardamineae (Brassicaceae) unraveled with HPLC-MS/MS and NMR-based analytical distinction of 70 desulfoglucosinolates. Phytochemistry. 2016;132: 33-56.

45. Liu TJ, Zhang XH, Yang HH, Agerbirk N, Yang QY, Wang HP, et al. Aromatic glucosinolate biosynthesis pathway in Barbarea vulgaris and its response to Plutella xylostella infestation. Front Plant Sci. 2016;7(83). https://doi.org/10. 3389/fpls.2016.00083.

46. Li H, Hearne S, Bänziger M, Li Z, Wang J. Statistical properties of QTL linkage mapping in biparental genetic populations. Heredity. 2010;105:257-67.

47. Hansen BG, Kerwin RE, Ober JA, Lambrix VM, Mitchell-Olds T, Gershenzon J. B.a. et al. a novel 2-oxoacid-dependent dioxygenase involved in the formation of the goiterogenic 2-hydroxybut-3-enyl glucosinolate and generalist insect resistance in Arabidopsis. Plant Physiol. 2008;148:2096-108.

48. Kliebenstein DJ, Cacho NI. Nonlinear selection and a blend of convergent, divergent and parallel evolution shapes natural variation in glucosinolates. Adv Bot Res. 2006;80:31-55.

49. Possenti M, Baima S, Raffo A, Durazzo A, Giusti AM, Natella F. Glucosinolates in food. In: Mérillon J-M, Ramawat KG, editors. Glucosinolates. Ref. Ser. Phytochem; 2017. p. 87-132. https://doi.org/10.1007/978-3-319-25462-3_4.

50. Pfalz M, Mikkelsen MD, Bednarek P, Olsen CE, Halkier BA, Kroymann J. Metabolic engineering in Nicotiana benthamiana reveals key enzyme functions in Arabidopsis indole glucosinolate modification. Plant Cell. 2011;23:716-29.

51. Pfalz M, Mukhaimar M, Perreau F, Kirk J, Hansen Cl, Olsen CE, et al. Methyl transfer in glucosinolate biosynthesis mediated by indole glucosinolate Omethyltransferase 5. Plant Physiol. 2016;172(4):2190-203.

52. Agerbirk N, Olsen CE, Cipollini D, Ørgaard M, Linde-Laursen I, Chew F. Specific glucosinolate analysis reveals variable levels of epimeric glucobarbarins, dietary precursors of 5-phenyloxazolidine-2-thiones, in watercress types with contrasting chromosome numbers. J Agr Food Chem. 2014;62:9586-96.

53. Gutiérrez-Velázquez MV, Almaraz-Abarca N, Herrera-Arrieta Y, Ávila-Reyes JA, González-Valdez LS, Torres-Ricario R. Comparison of the phenolic contents and epigenetic and genetic variability of wild and cultivated watercress (Rorippa nasturtium var. aquaticum L.). Electron J Biotechnol. 2018;34:9-16.

54. Jeon J, Bong S, Park J, Park Y, Arasu MV, Al-Dhabi NA, et al. De novo transcriptome analysis and glucosinolate profiling in watercress (Nasturtium officinale R. Br.). BMC Genomics. 2017;18(401) https://doi.org/10.1186/ s12864-017-3792-5.

55. Voutsina N, Payne AC, Hancock RD, Clarkson GJJ, Rothwell SD, Chapman MA, et al. Characterization of the watercress (Nasturtium officinale R. Br: Brassicaceae) transcriptome using RNASeq and identification of candidate genes for important phytonutrient traits linked to human health. BMC Genomics. 2016;17(378) https://doi.org/10.1186/s12864-016-2704-4.

56. van Leur H, Raaijmakers CE, van Dam NM. A heritable glucosinolate polymorphism within natural populations of Barbarea vulgaris. Phytochemistry. 2006;67:1214-23.

57. van Leur H, Vet LEM, Putten WHVD, Dam NMV. Barbarea vulgaris glucosinolate phenotypes differentially affect performance and preference of two different species of lepidopteran herbivores. J Chem Ecol. 2008;34: $121-31$.

58. Müller C, Schulz M, Pagnotta E, Ugolini L, Yang T, Matthes A, et al. The role of the glucosinolate-myrosinase system in mediating greater resistance of Barbarea verna than B. vulgaris to Mamestra brassicae larvae. J Chem Ecol. 2018;44:1190-2005 https://doi.org/10.1007/s10886-018-1016-3.

59. Burow M, Halkier BA. How does a plant orchestrate defense in time and space? Using glucosinolates in Arabidopsis as case study. Curr Opin Plant Bio. 2017;38:142-7.

60. Doyle J, Doyle J. Genomic plant DNA preparation from fresh tissue-CTAB method. Phytochem Bull. 1987;19:11-5.

61. Li W, Godzik A. Cd-hit: a fast program for clustering and comparing large sets of protein or nucleotide sequences. Bioinformatics. 2006;22:1658-9.

62. Zerbino DR, Birney E. Velvet: algorithms for de novo short read assembly using de Bruijn graphs. Genome Res. 2008;18:821-9.

63. Li H, Durbin R. Fast and accurate short read alignment with burrowswheeler transform. Bioinformatics. 2009;25:1754-60.

64. Li H, Handsaker B, Wysoker A, Fennell T, Ruan J, Homer N, et al. The sequence alignment/map format and SAMtools. Bioinformatics. 2009;25:2078-9.

65. Van Tassell CP, Smith TP, Matukumalli LK, Taylor JF, Schnabel RD, Lawley CT, et al. SNP discovery and allele frequency estimation by deep sequencing of reduced representation libraries. Nat Methods. 2008:5:247-52.

66. Kundu A, Chakraborty A, Mandal NA, Das D, Karmakar PG, Singh NK, et al. A restriction-site-associated DNA (RAD) linkage map, comparative genomics and identification of QTL for histological fibre content coincident with those for retted bast fibre yield and its major components in jute (Corchorus olitorius L., Malvaceae s.l.). Mol Breeding. 2015;35:1-17.

67. Van Ooijen J. JoinMap ${ }^{\oplus}$, software for the calculation of genetic linkage maps in experimental populations, Kyazma BV. Wageningen; 2006.

68. Voorrips RE. MapChart: software for the graphical presentation of linkage maps and QTL. J Hered. 2002;93:77-8.

69. de l'Eclairage Cl. Recommendations on uniform color spaces-color difference equations, psyhometric color terms. Supplement No. 2 to CIE Publication No. 15 (E.-1.3. 1) 1971/(TC-1.3.). 1978.

70. Wang S, Basten C, Zeng Z. Windows QTL cartographer v2, vol. 5. Raleigh, NC: Department of Statistics, North Carolina State University; 2012.

71. Churchill GA, Doerge RW. Empirical threshold values for quantitative trait mapping. Genetics. 1994;138:963-71. 